\title{
O Museu de Arte Sacra e Etnologia como atrativo turístico (Fátima, Portugal)
}

\author{
The Museum of Sacred Art and Ethnology as tourist attraction in Fátima \\ (Portugal)
}

\author{
Eunice Ramos Lopes (LOPES, E. R.) ${ }^{*}$
}

\begin{abstract}
RESUMO - A Organização Mundial do Turismo (OMT) aponta os museus como tendo um papel decisivo na reafirmação das narrativas e significados históricos e culturais a apropriar/a fruir pelos visitantes, pelos turistas, pela comunidade local, por exemplo. Evidenciar as motivações e as experiências dos visitantes, em torno da cultura material exibida no Museu de Arte Sacra e Etnologia de Fátima (MASE, Portugal), é o que se pretende ressaltar neste artigo. $\mathrm{O}$ museu exibe objetos de arte sacra e também objetos etnográficos oriundos de África, América e Ásia. A metodologia encontra-se fundamentada no trabalho de campo efetuado no museu, com observação participante, análise de conteúdo ao livro de "opiniões dos visitantes" e aplicação de questionário aos visitantes (nacionais e estrangeiros). Os resultados finais encontrados reforçam, não só a importância da função social do MASE (através do acervo e coleções, essenciais para a divulgação da cultura da região e, particularmente, para a divulgação de objetos etnográficos de povos de várias regiões do mundo), como também, a importância do museu como atrativo turístico.
\end{abstract}

Palavras-chave: Turismo; Museologia; Objetos etnográficos.

ABSTRACT - The World Tourism Organization (WTO) points the museum as having a decisive role in the reaffirmation of the narratives and historical and cultural meanings to appropriate/to fruition by visitors, tourists and local community, for example. The intention of this paper is to demonstrate the tourist and visitors motivations and experiences around the material culture displayed at the Museum of Sacred Art and Ethnology (MASE) located in Fatima. The museum displays objects of religious art as well as ethnographic objects from Africa, America and Asia. The methodology is based on field research carried out in the museum, with participant observation, content analysis of the "opinions of visitors" book and a questionnaire applied to the visitors. The final results found not only reaffirm the importance of the social function of MASE (throughout the collections, essential for spreading the culture of the region and particularly for the dissemination of ethnographic objects from people of several regions around the world), but also the importance of the museum as a tourist attraction.

Key words: Tourism; Museology; Ethnographic objects.

\footnotetext{
* Licenciatura em Conservação e Restauro pela Escola Superior de Tecnologia de Tomar (ESTT, Portugal). Mestrado em Museologia e Património pela Universidade Nova de Lisboa (UNL, Portugal). Doutoranda em Políticas, Imagens da Cultura e Museologia pela Universidade Nova de Lisboa (UNL, Portugal). Docente Assistente no Curso de Licenciatura em Gestão Turística e Cultural da Escola Superior de Gestão do Instituto Politécnico de Tomar (ESGT-IPT). Endereço Postal: IPT-ESG, Quinta do Contador, 2300-313, Tomar (Portugal). Telefone: (351) 249328100. E-mail: eunicelopes@ipt.pt.Web:http://www.ipt.pt.
} 


\section{INTRODUÇÃO}

As novas tendências apontam para um turismo mais motivado para o consumo cultural, para a experimentação e emoções, para os sentimentos e valorização da "autenticidade". A propósito desta tendência, têm sido apresentadas diversas tipologias de turismo e, motivações do turista, como as esboçadas por Valene Smith (1989) ou as de Erik Cohen (1972), que classificam os turistas de acordo com as experiências turísticas. Segundo Bendix (2003) a narrativa das memórias, molda e estrutura a experiência turística. Evocando o museu como centro de representação e dinamizador do património, Sharpley (1994) defende que, se o património histórico-cultural possibilita a continuidade da experiência humana, o turismo possibilita a vivência dessa experiência. Boiteux e Werner destacam que "o turismo é uma vivência cultural que seduz pela diversidade, marco principal do produto turístico, e que gera a deslocação de turistas" (BOITEUX; WERNER, 2002, p. 107). O fenómeno museológico contemporâneo é um elemento privilegiado para os processos de construção de significados, de representação e de consumo cultural Pearce (1982) e, neste sentido, a Organização Mundial do Turismo (OMT, 2001), aponta o museu como tendo um papel decisivo na reafirmação das narrativas e significados históricos e culturais. Os visitantes ao entrarem em contacto com um acervo de museu otimizam o seu gaze turístico - que, segundo Urry (1990) se estende cada vez mais "desdiferenciado".

Baseado no trabalho de campo desenvolvido no Museu de Arte Sacra e Etnologia $^{1}$ procurou-se evidenciar as motivações e as experiências de turistas e visitantes, em torno da cultura material exibida. $\mathrm{O}$ museu exibe objetos de arte sacra e também objetos etnográficos oriundos de África, América e Ásia. Por isso, o MASE tem como propósito:

\footnotetext{
Mostrar as expressões culturais que revelem a diversidade e os pontos de contacto que traduzem as relações entre os povos. Pretende-se igualmente despertar e cultivar nas pessoas e na sociedade contemporânea, sentimentos de solidariedade e de fraternidade que atingirão a sua expressão mais alta na missionação e na partilha de bens (MASE, 2006, p. 2).
}

\footnotetext{
${ }^{1}$ O trabalho foi desenvolvido durante o ano 2010 - 2011. Doravante, para se designar o Museu de Arte Sacra e Etnologia, recorrer-se-á à sigla MASE. O museu situa-se em Fátima, pertencendo ao Distrito de Santarém (área administrativa), à Diocese de Leiria-Fatima (área eclesiástica) e ao concelho de Ourém. Tutela do MASE: Delegação Portuguesa do Instituto Missionário da Consolata (IMC). Foi inaugurado a 13 de Outubro de 1991 e integra a Rede Portuguesa de Museus - RPM. (MASE, 2006, p. 2).
} 
O museu dispõe de cinco salas com exposições permanentes e uma sala com exposições temporárias (Quadro 1 - espaços do museu).

\begin{tabular}{|c|c|c|}
\hline $\mathbf{N}^{\mathbf{o}}$ & Espaços & Breve descrição \\
\hline 0 & Receção & --- \\
\hline 1 & \multirow[t]{2}{*}{ Sala da Natividade } & \multirow{2}{*}{$\begin{array}{l}\text { Apresenta uma vasta coleção de presépios e imagens da } \\
\text { infância de Jesus, de madeira, terracota, marfim e estanho. As } \\
\text { mais antigas datam do século XVI e são, na sua maioria, } \\
\text { portuguesas e indo-portuguesas. }\end{array}$} \\
\hline 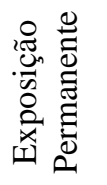 & & \\
\hline 2 & \multirow[t]{2}{*}{ Sala da Paixão } & \multirow{2}{*}{$\begin{array}{l}\text { Apresenta uma coleção de figuras relativas à paixão e morte } \\
\text { de Cristo e crucifixos dos séculos XIV ao XX. São de origem } \\
\text { portuguesa, indo e sino portuguesas. Encontram-se } \\
\text { igualmente exibidos paramentos, alfaias litúrgicas e oratórios } \\
\text { que demonstram as tradições devocionais portuguesas. }\end{array}$} \\
\hline 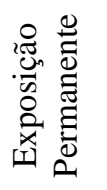 & & \\
\hline 3 & \multirow[t]{2}{*}{ Sala da Missão } & \multirow{2}{*}{$\begin{array}{l}\text { Apresenta o caminho percorrido pelo Evangelho desde o } \\
\text { Pentecostes em Jerusalém até aos dias atuais, através de } \\
\text { vários objetos de arte, textos, mapas e reproduções } \\
\text { fotográficas dos diversos continentes. Coloca-se em } \\
\text { evidência, na história, a participação portuguesa na época dos } \\
\text { Descobrimentos e, na atualidade, a missão perante as culturas } \\
\text { e as religiões. }\end{array}$} \\
\hline 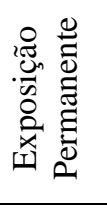 & & \\
\hline 4 & \multirow[t]{2}{*}{ Sala da Etnologia } & \multirow{2}{*}{$\begin{array}{l}\text { Apresenta uma rara coleção de objetos etnográficos de uso } \\
\text { quotidiano dos povos com quem os missionários tiveram/têm } \\
\text { contacto. Os mais significativos provêm da Amazónia, } \\
\text { Quénia, Zaire, Angola, Guiné, Moçambique e Extremo } \\
\text { Oriente. }\end{array}$} \\
\hline 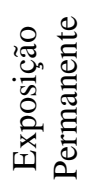 & & \\
\hline 5 & $\begin{array}{l}\text { Sala de exposições } \\
\text { Temporárias }\end{array}$ & $\begin{array}{l}\text { Esta sala para além de receber exposições organizadas pelo } \\
\text { MASE recebe também, exposições de artistas ou entidades } \\
\text { externas, desde que haja disponibilidade e que a temática se } \\
\text { enquadre na missão do museu. }\end{array}$ \\
\hline 6 & Capela & --- \\
\hline 7 & \multirow[t]{2}{*}{ Sala dos Pastorinhos } & \multirow{2}{*}{$\begin{array}{l}\text { Esta sala, inaugurada em 2000, apresenta a relíquia do Beato } \\
\text { Francisco Marto (barrete) oferecido aos Missionários da } \\
\text { Consolata (pelo seu pai) em 1956. Para além de outros objetos } \\
\text { pessoais do doador, na sala exibe-se uma pedra do túmulo de } \\
\text { Francisco e Jacinta onde repousaram antes da transladação } \\
\text { para a Basílica. }\end{array}$} \\
\hline 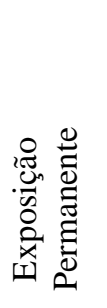 & & \\
\hline 8 & Auditório & --- \\
\hline 9 & Pátio / Jardim & --- \\
\hline
\end{tabular}

QUADRO 1 - ESPAÇOS DO MUSEU

FONTE: LOPES, E. R., 2011 (elaborado a partir de MASE, 2006, p. 5). 
O turismo, sendo uma atividade multifacetada/diversificada, intrinsecamente, encontra-se relacionado com os museus, como uma atividade que permite potenciar o papel dos museus como recurso turístico. Neste breve ensaio pretende-se apresentar alguns dados sobre as motivações e as experiências dos visitantes, em torno da cultura material exibida no MASE, pondo em destaque a importância do museu como atrativo turístico.

\section{O PERCURSO DOS VISITANTES PELO MUSEU}

Ao entrar no MASE, a música Golden Rose aclama aos sentidos, dirigindo os visitantes para a funcionária - rececionista, que informa sobre o preço de ingresso, provendo o suporte textual informativo (desdobrável) que permitirá aos visitantes sustentar o percurso museográfico.

Opção informativa paralela (roteiro), em vários idiomas (Espanhol, Francês, Italiano, Inglês, Alemão, Polaco), encontra-se do lado direito do corredor que vai dar ao início do percurso - Sala da Natividade (com um painel frontal, de cor azul), dando a demarcação dos núcleos expositivos seguintes.

Com a citação de palavras do Evangelho e com a variação da música de fundo, os visitantes encontram coleções de presépios e imagens da infância de Jesus, de madeira, terracota, marfim e estanho. As mais antigas datam do século XVI e são, na sua maioria, portuguesas e indo-portuguesas. Neste contexto, Penalva (2011, p. 16) assegura que estas coleções são:

\footnotetext{
Coadjuvantes numa história que se pretende narrar de forma que perdure na memória coletiva a título de inspiração ou de exemplo são as pequenas peças de metal como coroas, resplendores, varas, caldeirinhas, sapatinhos, enfim, uma infinidade de atributos que povoa a exposição permanente do museu. São, de facto, estes detalhes ou complementos narrativos que permitem a um devoto o imediato reconhecimento da imagem cultuada [...] são, assim, a expressão de um artista e de uma devoção, reunindo em si duas importantes vertentes, a Arte e a Fé.
}

$\mathrm{Na}$ estratégia museográfica recorre-se ao uso de vitrinas reunidas no centro da sala, distribuídas pelo espaço ou ainda adossadas às paredes. Aos objetos exibidos atribuem-se legendas, que incluem a designação/título, material e técnica de fabrico, 
data, proveniência e número de inventário. Juntam-se, ainda, informações textuais e iconográficas (exemplo: reprodução fotográfica - pintura, "A Virgem e o menino, século $X V^{\prime}$, de Hans Nemling, Museu Nacional de Arte Antiga), forma de reforçar, não só a temática - a Natividade, mas, igualmente a mensagem expositiva.

Os visitantes ao aproximarem-se da segunda Sala - a da Paixão e Morte de Cristo, transição, evidenciada, como na primeira sala (através de painel, agora, de cor vermelha), podem continuar o seu percurso seguindo a narrativa bíblica, "revivendo", este ciclo da Paixão, conforme Franco e Vilhena de Carvalho (2011, p. 36) o designam, e que é,

[...] Pontuado por uma escultura que representa a figura de Cristo morto, com a qual termina a própria narrativa sagrada que pode "reviver-se" nesta sala do Museu de Arte Sacra e Etnologia.

A música de fundo continua a impelir os visitantes a prosseguirem e a intensificarem o "olhar" para as figuras de Cristo. A iluminação sobre os objetos consolida o cenário. Paralelamente, os diversos textos os documentam.

Como os materiais em que os Cristos são executados são os mais diversos. Se o alabastro poderá ser considerado um suporte ideal para o escultor informado e formado na tradição italiana classicista, o marfim, em que doze das obras foram esculpidas, empurrará o seu universo de origem para as possessões portuguesas no Índico (FRANCO e VILHENA DE CARVALHO, 2011, p. 34).

A organização espacial expositiva continua a formar-se com a representação da Virgem da Piedade - a "Pietá" (Legenda: José Ferreira Thedim (1892- 1971), madeira policromada, 1927. Peça premiada na Secção de Belas Artes da Exposição IberoAmericana de Sevilha em 1927). Ainda na mesma sala, os crucifixos datam dos séculos XIV ao XX. São de origem portuguesa, indo e sino portuguesas. Igualmente, alfaias litúrgicas, oratórios e paramentos, demonstram as tradições devocionais portuguesas. Como refere Rodrigues (2011, p. 52) são,

Peças imbuídas de um sentido e significado, técnica e presença, beleza e cor, os paramentos são importantes adereços cénicos, nesta sala exemplificados através de espécimes de distintas tipologias (casulas, dalmáticas, pluvial e outras peças da coleção têxtil do Museu) datados de entre o século XVII e o século XIX. 
A abertura transitória para o espaço expositivo seguinte é dada pelo "Canto Gregoriano", de fundo (e, pelo painel de cor verde), introduzindo os visitantes para a Sala da Missão. O esquema museográfico altera-se um pouco - aos objetos de arte sacra é dado agora destaque aos mapas, aos gráficos e às reproduções fotográficas dos diversos continentes - transportando os visitantes pelos caminhos representativos da missionação, a que Matias e Duarte (2011, p. 56) igualam a,

Terras asiáticas, lugar de panteões mais antigos que a própria missionação e que com ela coabitaram, mas lugar de implantação da mensagem que os missionários levaram as paragens tão longínquas.

O fio condutor expositivo continua, através da exibição da maqueta da Catedral de S. Tomé, elaborada com miolo de palmeira (figura 1). Ainda, um Altar Doméstico com Divindade Budista, em posição de meditação, em talha dourada, madeira policromada, proveniente de Macau. China. Sociedade Missionária Portuguesa (figura 2).

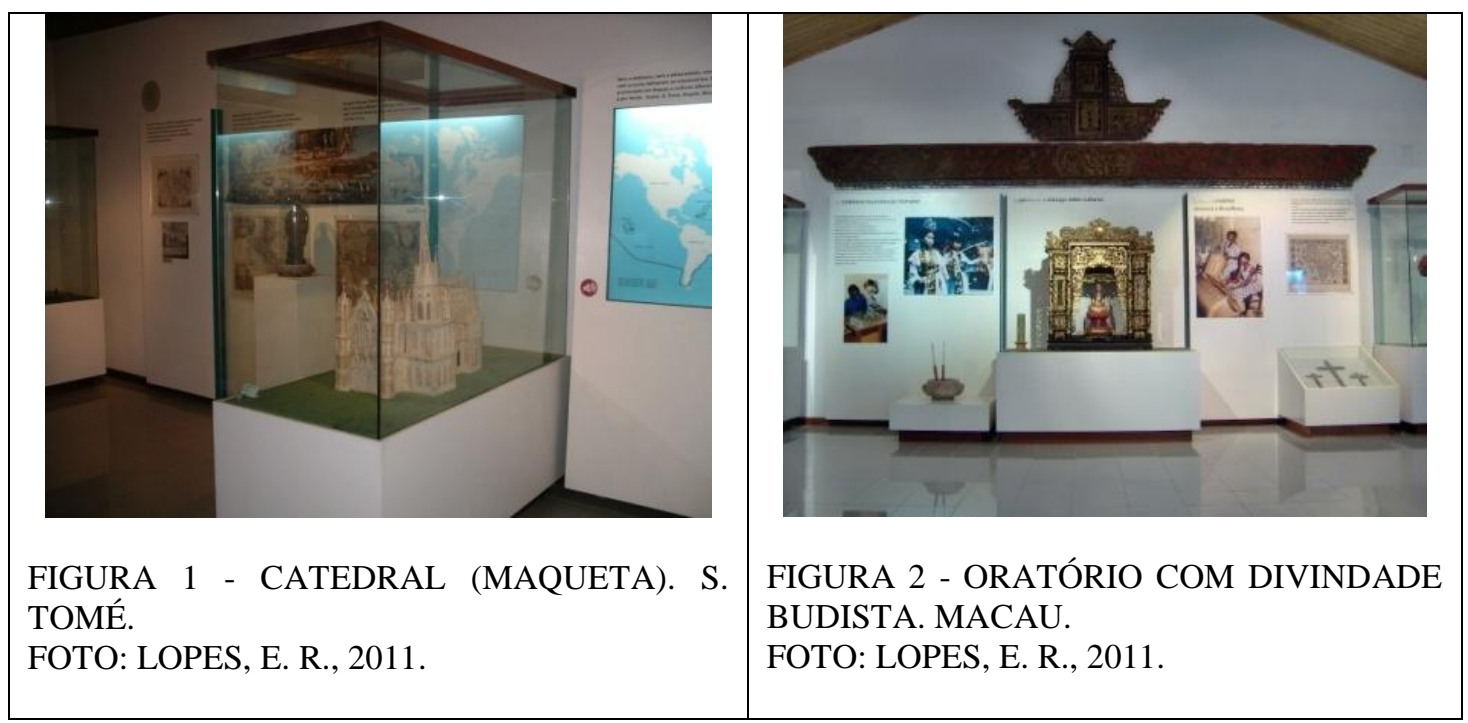

Prosseguindo para a Sala de Etnografia (demarcação visível, mais uma vez, pelo painel cor de laranja) e a partir das mensagens: "encontro de gentes e culturas" e "o espírito que infunde as "sementes do verbo", presentes nos ritos e nas culturas, e as faz maturar em Cristo", os visitantes entram num espaço em que podem observar objetos etnográficos de uso quotidiano dos povos com quem os missionários tiveram/têm 
contato (figura 4, 5 e 6). Estes objetos etnográficos são, como referem Matias e Duarte (2011, p. 56):

Reveladores de histórias de vida, mas também das próprias sociedades que os produziram e utilizaram, os objetos das Coleções Etnográficas do MASE refletem uma amplitude e diversidade espacial e cultural.

O percurso ainda não está completo, pois à medida que os visitantes se encaminham para o final da visita, deparam-se com uma representação dos Passos da Vida de Cristo, em Ébano, do séc. XX (finais), proveniente da Tanzânia (figura 4).

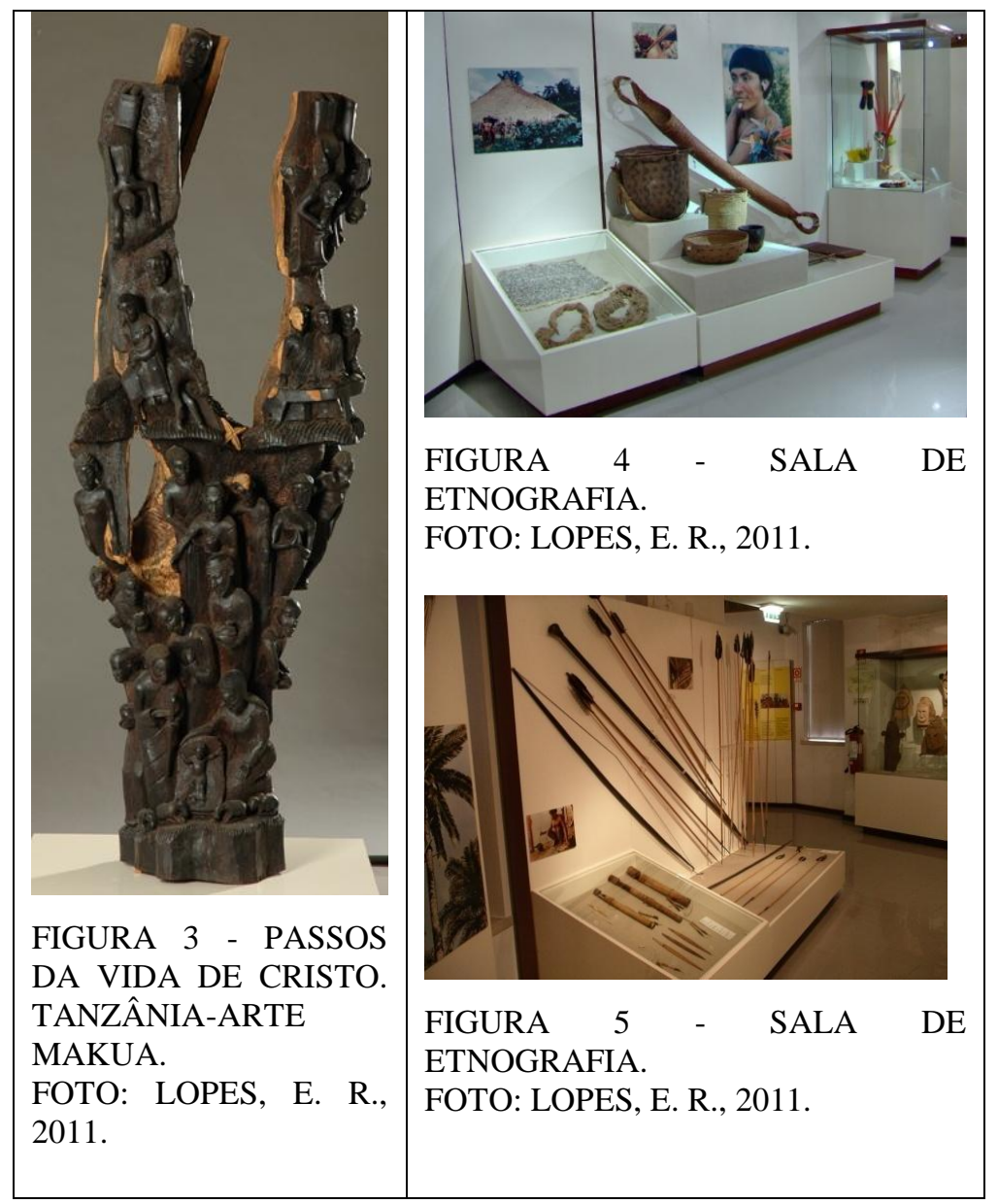

A melodia mística chama os visitantes para a última sala - a dos Pastorinhos (inaugurada em 2000), cujo propósito seria apresentar símbolos associados às Aparições de Fátima. Trata-se de um espaço expositivo de reduzida dimensão, onde domina um ambiente cenográfico de "mistério", conseguido pela cor escura das paredes, apenas 
com focos de luz a incidir sobre o "barrete" do Beato Francisco Marto, oferecido aos Missionários da Consolata pelo seu pai (“Ti Marto”, assim conhecido) em 1956.

Para além de outros objetos pessoais do doador, esta sala, exibe uma pedra do túmulo de Francisco e Jacinta onde repousaram antes da transladação para a Basílica de Fátima, que segundo Duarte (2011, p. 10), considera, é:

\begin{abstract}
Um pequeno núcleo que faz o remate deste grande rio, uma espécie de foz apertada que recoloca o visitante no lugar que o trouxe a este museu: Fátima. Felizmente transplantado para a última parte do museu, o espaço, deliberadamente cenográfico, exibe vários objetos ligados à história de Fátima e dos seus protagonistas, sublinhando, uma vez mais, como os vestígios materiais fazem apelo ao conhecimento histórico da comunidade.
\end{abstract}

Esta é a última sala do percurso expositivo, e, por isso, o visitante, pode expressar-se sobre a sua experiência de visita ao museu através do "Livro de Visitas".

\title{
3 MOTIVOS DE VISITA AO MASE
}

Vários autores definem o turismo como um processo composto por motivações que variam de acordo com diferentes estágios (COHEN, 1972; PEARCE, 1982; PARRINELLO, 1993; SHACKLEY, 2001; WILLIAMS e BUSWELL, 2003). A motivação turística define "uma disposição mental significativa para viajar" (DANN, 1981, p. 189). Segundo Falk e Dierking (1992, p. 14) existem três tipos de motivações para visitar um museu: 1) razões sociais e recreativas, 2) razões educacionais, 3) razões "reverenciais", ou seja, a busca de objetos únicos e monumentos sacralizados.

A motivação é um fator fundamental do comportamento do visitante. Por isso, Dubois (2000, p. 57) classifica-a a três níveis: a) individual - as perceções, as experiências passadas, b) interpessoal - o ambiente envolvente, c) sociocultural - fatores como classe social ou cultura. Para Pearce (1982, p. 49) "as teorias de motivação têm desempenhado um papel importante no desenvolvimento da psicologia como campo de pesquisa". Certo que as motivações são o resultado de "interações específicas da pessoa e da situação e são processos e resultados com um maior grau de definição e adoção" (HECKHAUSEN, 1989, ob. cit. em GNOTH, 1997 e 1999, p. 248)². Enquanto isso, Gnoth (1997, p. 290-291) define a motivação do turismo como "fator de unidade

\footnotetext{
${ }^{2}$ HECKHAUSEN, H. Motivation und Handeln (2nd ed.). Berlin: Springer, 1989.
} 
interna, que leva o turista para localizar objetos, situações e eventos que caracterizam um determinado lugar".

Em geral, as motivações turísticas são "um reflexo da livre escolha, a liberdade de opinião e subjetividade inerente à realização de ações preferenciais de cada um" (SUVANTOLA, 2002; WILLIAMS e BUSWELL, 2003, p. 72). Neste contexto, o consumo e a prática cultural requereram uma análise baseada no uso social do MASE.

O uso do questionário evidenciou-se um instrumento fundamental, em termos de pesquisa empírica, para dar resposta a algumas interrogações que se formularam acerca dos visitantes e turistas que procuram o MASE. Para responder a esta questão procurouse estruturar um inquérito o mais básico possível, agenciando uma interpretação baseada numa abordagem mais espontânea refletida não só nos inquéritos mas, e, também, no "Livro de Opinião" dos visitantes.

A fim de proceder-se a uma análise mais prática que caracterizasse os visitantes do MASE foi aplicado um inquérito formado por um núcleo básico onde se incluiu questões em que, cuja resposta, resultasse em informações relativas ao perfil sociológico dos visitantes (sexo, idade, nacionalidade, residência e habilitações literárias). Tentando conhecer, também, a motivação do visitante (“Questão 6. Qual a principal razão da sua visita a este museu?") e, para além, da motivação, tentou-se, também, descortinar como os visitantes classificavam a sua prática ("Questão 7. Como classifica a prática que o trouxe ao museu?").

Os dados que se apresentam abaixo, baseiam-se numa análise a 181 inquéritos e incluem um período que vai desde o mês de Abril de 2010 ao mês de Dezembro de 2010. Sendo que serão referenciados apenas os dados relativos às questões 6 e 7 , os que interessam nesta abordagem.

No que concerne à motivação (Questão 6) a principal razão apresentada para visitar o MASE, foi de índole religiosa (46,4\%). As visitas motivadas pelo lazer e educativa, corresponderam, respetivamente, a (15,2\%) e (12,5\%). Também, 9,9\% dos respondentes consideraram que a principal motivação da visita ao museu era educativa/religiosa, 5,3\% consideraram religiosa/lazer, 3,8\% educativa/lazer e por fim, $2,7 \%$ consideraram que a visita ao museu envolvia três tipos de motivação educativa, religiosa e lazer. Ainda, $0,4 \%$ dos respondentes afirmaram que a curiosidade e o gosto eram também motivos que os conduziram ao museu. Quanto à classificação da prática 
(Questão 7), 55,9\% relacionaram a sua prática ao turismo religioso, $19,4 \%$ ao turismo cultural, $11 \%$, entre o turismo cultural e religioso, $8,7 \%$ associaram a sua prática ao turismo, $1,5 \%$ ao turismo e turismo religioso, $0,8 \%$ remeteram a sua prática para o turismo, o turismo cultural e o turismo religioso.

Assim, a motivação pode encontrar-se ligada ao desejo de encontrar algo diferente, algo exótico ou até encontrar um reconforto espiritual. Também pode encontrar-se ligada ao encontro das delícias de um sonho, como descreve Urry (2001, p. $13)$ :

\begin{abstract}
A motivação básica de consumo do povo não é simplesmente razões materialistas. Pelo contrário, procuram experimentar aspetos mais agradáveis já experienciados através do sonho/da imaginação. Há uma dialética permanente entre o novo e a busca dos prazeres sonhados que estão na parte inferior do consumismo contemporâneo.
\end{abstract}

\title{
4 EXPERIÊNCIA DOS VISITANTES DO MASE
}

Num mundo globalizado, altamente diversificado culturalmente há um processo de desenvolvimento social que, na maioria das vezes, é carente de uma reflexão crítica, e, neste, sentido, o museu é de fundamental importância, visto que o espaço museológico pode tornar-se num terreno despoletador desta capacidade de análise e reflexão.

Urry (2001, p. 76) reflete sobre "como e porquê durante certos períodos as pessoas deixam os seus locais de residência para consumir bens, serviços e viver experiências que são, aparentemente, desnecessárias”. Esta sua preocupação/reflexão pode ser dirigida para o museu - deve ser compreendido como integrante do processo de formação do cidadão e da sociedade - um produtor de conhecimentos comprometido socialmente. No entanto, há outras interligações que não devem ser deixadas de lado pensar o turismo enquanto atividade socioeconómica, como Urry (2001, p. 78), por exemplo, refere.

De onde vem a riqueza dessa experiência para os seres humanos, que não existe um único olhar do turista enquanto tal, que este é socialmente organizado e que sua sistematização depende das experiências acumuladas na vida quotidiana, ou seja, a forma como funciona o "olhar turístico" depende de todas as construções sociais e experiências pelas quais as pessoas passam devido às suas origens, famílias, profissão, local de residência, entre outras. 
Margarida Lima de Faria (2001), também a este propósito, identifica sete necessidades sociais que, podem contribuir para a definição das funções sociais do museu dentro da sociedade portuguesa:

\section{Função identitária, função de sociabilidade; função de participação cívica; função de solidariedade; função de inclusão multicultural; função de informação; função de aquisição/ transmissão de conhecimento de modo crítico e de acordo com múltiplas leituras. (FARIA, 2001, p. 25-27).}

Neste sentido, Hopper-Greenhill (1994, p. 141) sustenta que “os museus são lugares onde não existem muitos dos constrangimentos que caracterizam outros locais de aprendizagem" e, nesta medida, os museus são considerados espaços únicos onde os objetos exibidos e as ideias podem ser explorados e as disciplinas livremente relacionadas. Através dos registos deixados no "Livro de Opinião" pelos visitantes do MASE (tendo em conta a tipologia, missão e objetivos do museu) apresentam-se algumas experiências ${ }^{3}$, a título de exemplo.

a) Encanto para com o museu:

- "Excelente! Do encontro de culturas à tolerância!".

- "Impressionante: nunca sonhei que poderia ver coisa que tocou tanto na fé".

- "Só tenho uma palavra a dizer: emocionante".

- “Agradável surpresa. Museografia em concordância com a mensagem e o espírito da missão religiosa".

- "Uma exposição encantadora de agradáveis experiências: é simples, humana e divina".

- "Fiquei maravilhado. É um modo de evangelização e de relação intercultural e espiritual. É tentativa de diálogo ecuménico".

b) Desencanto para com o museu:

- "Gostei, mas penso que os budas não deviam aqui estar".

- "Sente-se espiritualidade nestas visitas, pelo que é de realçar a oportunidade e utilidade destas exposições. A única parte negativa, na minha opinião, foi introduzir budas, no final da exposição. Não deverá haver misturas".

\footnotetext{
${ }^{3}$ Transcrições do "Livro de Opinião" dos visitantes conforme as originais.
} 
- "O museu é muito interessante mas acho que deveriam existir mais explicações acerca de alguns objetos em exposição. Por exemplo, numa das últimas secções acerca dos materiais utilizados pelos povos africanos deveria estar mais explicito o tipo de utilização dado a certos materiais"

- "Poderiam criar um sistema áudio para os invisuais, pois a experiência a todos pertence".

A simbiose entre cultura e sagrado encontram-se nestas experiências registadas no "Livro de Opinião" dos visitantes do museu. No momento, atual, o museu deve centrar-se nos visitantes, nos significados que impõem às experiências e nas perceções que assimilam em relação à cultura material exibida. Como recorda Faria (2001, p. 27):

\begin{abstract}
Numa altura em que os museus se vêem a braços com uma crescente concorrência das novas formas de entretenimento produzidas como resultado dos avanços tecnológicos de uma indústria da cultura em expansão, o sentido que atribuem ao público é cada vez mais o de um consumidor exigente cujas aspirações em relação ao museu, importa conhecer e respeitar. Aposta-se crescentemente na diversidade de propostas para responder a uma diversidade de expectativas por parte do visitante.
\end{abstract}

Ao museu importa captar a linguagem que uma coleção, uma imagem, um artefacto expressa, significa, abrir um diálogo, perspetivando que conte o passado que foi, o que representa no presente e até o que poderá vir a ser no futuro (PÉREZ e HERVÁS, 2001).

Através de um discurso museológico apostado na rejeição de estereótipos e preconceitos, o MASE continua a sua missão de dar a fruir objetos de arte e objetos etnográficos, evidenciando o espírito de Hein "museums are extraordinary places where visitors have an incredible range of experiences" (HEIN, 1998, p. 2).

\title{
5 CONSIDERAÇÕES FINAIS
}

O MASE enquanto atrativo turístico (em função do acervo e coleções para a divulgação da cultura da região e, particularmente, para a divulgação de objetos etnográficos de povos de várias regiões do mundo) conquista os visitantes, ajudando-os a percorrer um caminho que não só lhes permite conhecer outros lugares e culturas, como também lhes permite um autoconhecimento, fortalecendo o processo de 
proximidade do "eu" com o museu, com o espiritual, com a comunidade local. O museu detém um papel decisivo na reafirmação das narrativas e significados históricos e culturais, a apropriar, quer pelos visitantes em geral (nacional e estrangeiro), quer pela comunidade local. Destacado por Clifford (utilizando a moldura teórica de Pratt, 1992), a importância que é atribuída aos museus, dirigi-os para questões como o pluralismo cultural ou a globalização e, deste modo, emergem como "zonas de contato locais/globais, sítios de construção de identidade e de transculturalidade de contenção e de excesso, 'epitomizam' o futuro ambíguo da diferença cultural” (CLIFFORD, 1997, p. 219).

Baseado nas motivações e nas experiências evidenciadas pelo terreno museológico que se tem vindo a apresentar, demonstra-se que o fenómeno social contemporâneo apela ao mundo espiritual (muitas vezes desligado de uma instituição religiosa) e, intensificando-se pela fruição da arte e da cultura material exibida, (re) absorvida por identidades múltiplas. Na verdade, neste trabalho, com observação participante ativa, assistiu-se a um processo de instigação motivacional, emocional, espiritual, etc., despoletado pelo percurso museológico e experiências vividas no museu. Isso demonstra a dialogia e o hibridismo que o museu estimula, levando os visitantes (a partir das mais diferentes motivações) a vivenciarem o espaço museológico não como espaço rígido e hegemónico de disseminação de conhecimento, mas antes como espaço de encontro transcultural, onde diferentes indivíduos, grupos e comunidades se cruzam, interagem e se influenciam reciprocamente.

\section{REFERÊNCIAS}

BENDIX, R. Capitalizing on memories past, present, and future. Observations on the intertwining of tourism and narration. Anthropological Theory. Vol 2(4), 2003.

BOITEUX, B. e WERNER, M. Promoção, entretenimento e planejamento turístico. Editora Aleph, São Paulo, 2002.

CLIFFORD, J. Spatial Practices: Fieldwork, Travel, and the Discipline of Anthropology in routes. Travel and translation in the Late Twenthieth Century. Harvard University Press. Cambridge Massachussetts London, England, 1997. 
COHEN, E. Towards a sociology of international tourism. Social Research, 39, (1), 1972.

DANN, G. Tourist motivation: An appraisal. Annals of Tourism Research, Vol. 8, No.2. 1981.

DUARTE, M. D. Roteiro. Museu de Arte Sacra e Etnologia. Fátima, 2011.

DUBOIS, B. Understanding the Consumer. Pearson Education Limited, Harlow, 2000.

FALK , J. DIERKING, L., The museum experience, Washington: Whalesback Books, 1992.

FARIA, M. L. A Função social dos museus. Conferência internacional - A Cultura em acção: impactos sociais e território, Porto, 25-27 de Outubro, 2001.

FRANCO, A. e VILHENA DE CARVALHO, M.J. Roteiro. Museu de Arte Sacra e Etnologia. Fátima, 2011.

GNOTH, J. Tourism expectation formation: the case of campervan tourists in New Zealand. Pizam, A. \& Mansfeld, Y. (eds.) Consumer Behaviour in Travel and Tourism. The Haworth Press, New York, 1999.

Tourism motivation and expectation formation. Annals of Tourism Research, 24 (2), 1997.

HEIN, G. Learning in the Museum, Routledge, Nova Iorque, 1998.

HOPPER-GREENHILL, E. Museums and their Visitors. London: Routledge, 1994.

MASE. Livro de Opiniões. Fátima, s.d.

Regulamento Interno. Fátima. 2006.

MATIAS, I. e DUARTE, M. D. Roteiro. Museu de Arte Sacra e Etnologia. Fátima, 2011.

OMT, Cultural Heritage and Tourism Development. A report on the international conference on Cultural Tourism, Madrid. 2001.

PARRINELLO, G. L. Motivation and anticipation in postindustrial tourism. Annals of Tourism Research, 20 (2), 1993.

PEARCE, P. The Social Psychology of Tourist Behaviour. Pergamon Press, Ltd.Oxford, 1982.

PENALVA, L. Roteiro. Museu de Arte Sacra e Etnologia. Fátima, 2011. 
PÉREZ, M. e HERVÁS, F. Mirar, Ver e interpretar el paisaje: una contribución al turismo cultural en Misiones, Abellánm, Aurelio (coord.) Turismo Cultural y desarrollo sostenible: Análisis de áreas patrimoniales. Universidad de Múrcia, 2001.

PRATT, M. L. Imperial Eyes: Travel Writing and Transculturation. London and New York: Routledge, 1992.

RODRIGUES, M. Roteiro. Museu de Arte Sacra e Etnologia. Fátima, 2011.

SHACKLEY, M. Managing Sacred Sites. Continuum, London, 2001.

SHARPLEY, R. Tourism, Tourists and Society, Cambridgeshire: ELM

Publications, Seaton House, England, 1994.

SUVANTOLA, J. Tourist's experience of place. Ashgate, Aldershot, 2002.

SMITH, V. Hosts and guests: the anthropology of tourism. Oxford: Brasil Blackwell, 1989.

URRY, J. Globalising the tourist gaze, Department of Sociology, Lancaster University, 2001.

.The Tourist Gaze: leisure and travel in contemporary societies, Sage Publications, London, 1990.

WILLIAMS, C. \& BUSWELL, J. Service Quality in Leisure and Tourism. CABI Pub, Wallingford, 2003.

Recebido em: 30-12-2011.

Aprovado em: 30-01-2012. 